\title{
Estimating Monetary Policy Effects When Interest Rates are Bounded at Zero
}

\author{
Shigeru Iwata and Shu Wu \\ The University of Kansas *
}

This version: March 2003

\begin{abstract}
Using a nonlinear structural VAR approach, we estimate the effects of exogenous monetary policy shocks in the presence of a zero lower bound constraint on nominal interest rates and examine the impact of such a constraint on the effectiveness of counter-cyclical monetary policies based on the data from Japan. We find that when interest rates are at zero, the output effect of exogenous shocks to monetary policy is cut in half if the central bank continues to target the interest rate. The conditional impulse response functions allow us to isolate the effect of monetary policy shocks operating through the interest rate channel when other possible channels of monetary transmission are present.
\end{abstract}

JEL Classification: E52 (Monetary Policy), E55 (Central Banks)

Key Words: Zero lower bound, monetary transmission, nonlinear VAR.

*Department of Economics, 213 Summerfield Hall, Lawrence, KS 66045. We are grateful to an anonymous referee for valuable suggestions and comments. We also like to thank seminar participants at the University of Kansas, the Midwest Econometric Group and the IMF, and especially John Keating for helpful comments. All errors are ours. Please send comments to Shigeru Iwata at iwata@ku.edu or to Shu Wu at shuwu@ku.edu 


\section{Introduction}

According to the standard Keynesian textbook model, an expansionary monetary policy leads to a decline in the real interest rate which in turn decreases the cost of capital, thereby causes a rise in consumer and investment spending and hence, raises aggregate demand and output. Many economists seem to agree that such an interest rate channel is the key component of how monetary policy shocks are transmitted to the real economy [e.g. Taylor (1995)]. However, since nominal interest rates cannot be lower than zero, one implication of such a transmission mechanism is that a liquidity trap would eliminate the effect of monetary shocks on the real economy. Once the nominal interest rate hits the zero value, monetary policy would become impotent when it is mostly needed.

The possibility that such a zero bound on interest rates might interfere with the conduct of monetary policy is not just a purely theoretical concern. For example, the recent experience of Japan, together with low inflation and a sharp decline in interest rates in many other countries in the past two decades, have brought the potential threat of deflation and the zero bound on nominal interest rates into focus. In the case of Japan, the overnight call rate, which is the policy instrument for the Bank of Japan, has been below 50 basis points since mid 1995, accompanied by economic stagnancy and deflationary pressure (see Figure 1). Such "zero interest rates" have not been observed in the United States and most other developed economies so far. However, with the recent phenomenon of low inflation, the argument that the effectiveness of monetary policy could be severely reduced with zero nominal interest rates no longer seems irrelevant.

These developments have given rise to a renewed interest in the implications of the zero lower bound for monetary policy. While most of the recent studies on this issue have relied on simulations of macro econometric models, this paper uses data on Japanese economy, which has experienced more than 5 years of "zero interest rates," to obtain empirical estimates of monetary policy effects when nominal interest rates hit the zero bound and to investigate the extent to which such a constraint might affect the ability of a central bank to conduct its policy. These empirical results would be useful in evaluating different policy options for the Japanese economy and allow us to draw lessons for other countries regarding the impact of the zero bound on monetary policy. 
Estimating the effects of monetary policy under the non-negativity constraints can also help us evaluate empirically the relative importance of different monetary transmission mechanisms. Many monetarist economists [e.g. Meltzer (1995)] have emphasized the importance of the monetary transmission mechanism operating through other asset prices. They argue that market interest rates are only one of the relative prices affected by monetary shocks. A monetary shock that alters the nominal and real stocks of money affects actual and anticipated prices of a variety of domestic and foreign assets, which in turn may affect investment and consumer spending through Tobin's q theory of investment and the wealth effect on consumption.

Some economists also view frictions in the credit markets due to asymmetric information as playing an important role in the process of monetary transmission [e.g. Bernanke and Gertler (1995)]. They argue that either through the balance sheet channel or the bank lending channel, a change in monetary policy can have an additional (and significant) impact on investment and consumer spending, and hence affects the aggregate demand and output.

The responses of the economy to monetary shocks most likely reflect the joint effect of different monetary transmission mechanisms, whose individual impact may be difficult to identify empirically. Nevertheless, observing zero interest rates provides an excellent opportunity to isolate the impact of monetary policy operating through the channels other than interest rates. Comparison of the responses of the economy to a monetary shock when the interest rate is at zero and when it is strictly positive would make possible an assessment of the importance of the interest rate channel.

Our study contributes to the recent literature on the zero bound on nominal interest rates. Using structural models of the U.S. economy, several authors perform numerical simulations to find the extent to which the zero bound prevents real rates from falling and hence affects the central bank's ability to optimally respond to adverse macroeconomic shocks. Fuhrer and Madigan (1997), Orphanides and Wieland (1998), and Reifschneider and Williams (2000) all find that monetary policy is significantly constrained by the zero bound under a policy regime with a low inflation target. Similar studies based on different models are conducted by Rotemberg and Woodford (1997) and Wolman (1998) with different conclusions about the importance of the zero bound as a constraint on monetary policy. The main objective of these studies is the normative implications for monetary policy 
of the zero bound. They try to evaluate "whether the zero bound introduce distortions that make low inflation undesirable". Most of the studies in this literature except Reifschneider and Williams (2000) have focused on the interest rate channel of monetary transmission.

In contrast, our study is based on direct empirical evidence on macroeconomic performance in a "zero interest rates" environment. Using the structural VAR approach, we examine to what extent the zero bound may affect a central bank's policy effectiveness when allowing for other channels of monetary transmission. Moreover, through state dependent impulse-response functions, we evaluate the relative importance of different monetary transmission channels. The paper also has a technical contribution to the structural VAR literature. It introduces a type of nonlinearity into a standard VAR model by incorporating a censored left hand variable.

Another strand of the zero interest rate literature focuses on the theoretical issue of how to avoid the zero bound and a liquidity trap and how to escape from them if trapped, usually with specific references to Japan. While many agree on how to avoid them, a variety of ways to get out of a liquidity trap are proposed, emphasizing different channels of monetary transmission [e.g Buiter and Panigirtzoglou (1999), Christiano (1999), Krugman (1998), McCallum (2000a) and Svensson (2000) among others].

The rest of the paper is organized as follows. Section 2 describes the data used in this study. Section 3 discusses our econometric strategy. Section 4 presents the main results and section 5 concludes.

\section{The Data}

Since the collapse of the speculative asset price bubble in early 1990, Japan has suffered prolonged deflation and economic stagnancy. Figure 1 exhibits industrial production and overall wholesale price together with the interbank call rates in Japan during 1990s. It can be seen clearly that output has failed to grow during the past decade while price level has been continuously declining (see Figure 1, both output and price are measured on the left scale). Such economic distress has prompted the Bank of Japan (BoJ) to adopt an expansionary monetary policy by lowering nominal interest rates. By September 1995, the inter-bank call rate, which has been the policy instrument for the BoJ, was pushed down to below 50 basis points and

remained at that low level until the end of 2001 (Figure 1, measured on the 
right scale). The experience of Japanese monetary policy during this period therefore provides a good opportunity to study the impact on monetary policy of the zero bound constraint on nominal interest rates.

In this paper, we use a monthly data set from 1991 to 2001. The variables include the Japanese wholesale price index, an index of industrial production, the inter-bank overnight call rate, the aggregate money supply (M1) and the Nikkei stock market index. Data on the price level, the interest rate and the stock market price are obtained from the BoJ. Data on industrial production and M1 are obtained from International Financial Statistics of the IMF. A reason for our focus on the time period between 1991 and 2001 is to avoid major policy changes within the sample. There appear to be several structural changes in Japanese monetary policy during the past 30 years. For example, in the second half of 1980s, stabilizing the exchange rate seemed to be the main policy goal for the BoJ due to the Plaza Accord. Moreover, the dramatic rise in asset prices starting in late 1980s caused the BoJ to refocus its policy activities on asset prices. See Hertzel (1999) for a discussion of Japanese monetary policy since 1970s. After the burst of the asset price bubble in 1990, however, the main concern of the BoJ is to deal with deflation and to revive its domestic economic activity, and there does not seem to be any major structural change in its policy.

\section{The Model}

\subsection{VAR with a censored variable}

To examine the effect of monetary policy shocks on the economy when the nominal interest rate is at zero, we propose a nonlinear Vector Autoregression (VAR) model that incorporates a censored variable. The model allows us to estimate the impulse-response functions conditional on the level of the interest rate.

Before introducing our model in detail, we briefly describe the monetary policy practice of the Bank of Japan (BoJ) during the 1990s, a period when the BoJ explicitly uses a short-term nominal interest rate (the overnight inter-bank call rate) as the policy instrument. In the late 1990s, the BoJ adopted what they call "zero interest rate policy." 1 The goal of this policy is to avoid further intensifying deflationary pressures and stop the economic

\footnotetext{
${ }^{1}$ According to the BoJ, the zero interest rate policy covers the period from February
} 
downturn. The BoJ's firm commitment to the zero interest rate policy is reflected in the well-cited statement of the BoJ's official: "We (the BoJ) will continue the zero interest rate policy until we reach a situation where deflationary concerns are dispelled" (Governor Hayami's statement at a press conference on April 13, 1999). In short, the policy undertaken by the BoJ in the late 1990s is to move nominal interest rates down to a level as low as possible by satiating the money market with excess supply of funds. One important aspect of the zero interest rate policy is that an exogenous monetary easing will not result in any further movement in the interest rate when the rate is already on the zero lower bound. Therefore, while the stance of monetary policy can be directly measured by the interest rate when it is positive, the interest rate at zero is no longer an adequate indicator of the policy stance.

To model the behavior of the monetary authority in Japan described above, we propose the following specification. Let $R_{t}$ be a nominal shortterm interest rate and $R_{t}^{*}$ be a latent variable measuring the stance of monetary policy. ${ }^{2} R_{t}^{*}$ is in general not observable. However, under the monetary policy regime that uses the short-term interest rate as the operating target, $R_{t}^{*}$ is directly linked to $R_{t}$ through the relation

$$
R_{t}= \begin{cases}R_{t}^{*} & \text { if } R_{t}^{*} \geq c \\ c & \text { otherwise }\end{cases}
$$

where $c$ is a lower bound on the nominal interest rate at which $R_{t}$ is regarded as essentially zero. We will further discuss what value is the most appropriate for $c$ below. Equation (1) treats $R_{t}$ as a censored variable. It implies that, when used by the monetary authority as the policy instrument, the short-term interest rate provides a direct measure of the stance of monetary policy. However, if the monetary policy drives the interest rate down to zero, a further monetary easing will not affect the interest rate. Our focus is to identify exogenous monetary policy shocks to $R_{t}^{*}$ and estimate their

1999 to August 2000 when the call rate was pushed down to 2 - 3 basis points. In this study, we treat the whole period since late 1995 as the zero interest rate regime, during which the interest rate remains below 50 basis points. See below for further discussions.

\footnotetext{
${ }^{2}$ This paper is also related to an early paper by Avery (1979), who uses a latent variable to model monetary policy. The major difference is that Avery (1979) is mainly concerned with the endogenous determination of monetary policy by relating a set of "causal" macroeconomic variables to changes in money market "indicator" variables through a single dimension latent variable, while our focus is on identifying and estimating the effects of exogenous innovations to monetary policy.
} 
dynamic effects on key macroeconomic aggregates. ${ }^{3}$

To connect the above scheme to the macroeconomic shocks, consider a standard money market model as illustrated in Figure 2. When the interest rate is the operating target, we can describe the determination of the interest rate and money growth in terms of fundamental macroeconomic shocks by (we abstract from all the lagged variables that may also enter the equations)

$$
\begin{aligned}
R_{t}^{*} & =\beta_{1}^{\prime} \varepsilon_{t}^{Y}+\beta_{2} \varepsilon_{t}^{s} \\
\Delta m_{t} & =\alpha_{1}^{\prime} \varepsilon_{t}^{Y}-\alpha_{2} \varepsilon_{t}^{s}+\alpha_{3} \varepsilon_{t}^{d}
\end{aligned}
$$

where $\Delta m_{t}$ is the growth rate of money at time $t$. Note that the short-term interest rate $R_{t}$ is determined jointly by (1) and (2).

Equation (2) represents the monetary policy reaction function (or policy rule), where $\varepsilon_{t}^{Y}$ is a vector of innovations to the macroeconomic variables to which the central bank responds contemporaneously when setting the short-term interest rate. $\varepsilon_{t}^{s}$ is an exogenous monetary policy shock due to any discretionary actions that are not captured by the systematic monetary policy rule, and $\varepsilon_{t}^{d}$ in equation (3) stands for an exogenous money demand shock. When the interest rate is the policy instrument, the monetary authority fully accommodates money demand shocks so that $\varepsilon_{t}^{d}$ only affects money growth without having any immediate effect on the interest rate. On the other hand, the exogenous monetary policy shock $\varepsilon_{t}^{s}$ affects both the interest rate and money growth.

More specifically, equations (1) - (3) together imply that, when the interest rate is positive, an expansionary policy shock $\left(\varepsilon_{t}^{s}<0\right)$ decreases the interest rate and at the same time pushes up money growth. When the interest rate is initially on the zero bound, however, an expansionary policy shock $\left(\varepsilon_{t}^{s}<0\right)$ does not generate any movement in the interest rate, but leads to an increase in money growth. In other words, when the interest rate is positive, both the interest rate and money growth contain information about monetary policy actions in either direction. But under the zero interest rate regime, exogenous monetary expansions can only be reflected in the corresponding movements of money growth, while the interest rate remains on its lower bound.

The maintained assumption is that there is no structural change in the

\footnotetext{
${ }^{3} R_{t}^{*}$ can also be thought of as the interest rate level the monetary authority would set according to its policy rule if there were no lower bound on the interest rate, or the intended interest rate.
} 
policy rule during the whole sample period. We believe this is a reasonable assumption about the monetary policy behavior of the BoJ during the 1990s because there is no indication that the central bank has adopted an alternative operating procedure in its conduct of monetary policy after the interest rate had reached zero, despite that many economists have suggested that the monetary authority should take some quantitative measures in the presence of the zero interest rate. This allows us to address the central issue of how the monetary policy effects are altered when the interest rate reaches its lower bound but the central bank continues to follow the same policy rule. In a later section, we consider the alternative scenario in which the BoJ switches to target to money growth under the zero interest rate regime.

We now turn to the issue of what value is the most appropriate for $c$. In general, the call rate cannot become exactly zero because of the existence of various transaction costs. ${ }^{4}$ Those costs add up to 2-3 basis points. But the choice of the value for $c$ should be made to best describe the BoJ's policy rule. The BoJ has set the uncollateralized overnight call rate guideline at $0.50 \%$ for $1995-1998$ and at $0.25 \%$ after September 1998. Between February 1999 and July 2000, this lower bound was further pushed down to about $0.02-0.03 \%$. It therefore appears to be a good approximation to the actual policy behavior to model the rate as being censored or equivalently $R_{t}^{*} \leq R_{t}$ as long as the actual rate $R_{t}$ is less than 50 basis points. A glance at the plot of the actual rates in Figure 1 appears to suggest that a regime change had occurred in 1995 when the nominal rate hit 50 basis points. Moreover, it is also supported by Krugman (1997), which argues that at a nominal rate of $0.43 \%$ "the economy is clearly in a very good approximation to liquidity trap conditions." Accordingly, throughout this paper, we use the terms such as 'zero interest rate' or 'zero bound' even when the actual lower bound is not necessarily exactly equal to zero. ${ }^{5}$

The small VAR system we estimate consists of three groups of variables. The first group includes standard macroeconomic variables such as output and price. Monetary policy is assumed to respond to these variables contemporaneously. The second group are money market variables including a short-term nominal interest rate (the overnight inter-bank call rate is used in

\footnotetext{
${ }^{4}$ Okina and Oda (2000) discusses the details of various transaction costs for the overnight inter-bank borrowings in Japan.

${ }^{5}$ There is also a technical concern for the choice of the lower bound $c$. Throughout the sample covering the period of 1990 - 2001, there are only a few observations with the call rate being around 2 or 3 basis points. Hence it is impossible to get sensible estimates of policy impact in such a circumstance.
} 
this paper) and the growth rate of aggregate money. These variables contain information about the stance of monetary policy. The last group includes some broad financial market variables such as stock market indices. These are the variables that can potentially play important roles in the monetary transmission process as suggested by Meltzer (1995), particularly when the nominal interest rate is on the zero bound. However, monetary policy is assumed not to respond to these variables contemporaneously.

Denote three groups of variables mentioned above by $\mathbf{Y}_{t}, \mathbf{W}_{t}^{*}, \mathbf{X}_{t}$ respectively, where $\mathbf{Y}_{t}$ is a $k \times 1$ vector, $\mathbf{W}_{t}^{*}$ is an $l \times 1$ vector and $\mathbf{X}_{t}$ is an $n \times 1$ vector, and $m=k+l+n$. The VAR system is then given by

$$
\left[\begin{array}{c}
\mathbf{Y}_{t} \\
\mathbf{W}_{t}^{*} \\
\mathbf{X}_{t}
\end{array}\right]=\mathbf{B}(L)\left[\begin{array}{c}
\mathbf{Y}_{t} \\
\mathbf{W}_{t} \\
\mathbf{X}_{t}
\end{array}\right]+\mu+\mathbf{u}_{t}
$$

where $\mathbf{W}_{t}^{*}=\left(R_{t}^{*}, \Delta m_{t}\right)^{\prime}, \mathbf{W}_{t}=\left(R_{t}, \Delta m_{t}\right)^{\prime}, \mathbf{B}(L)=\mathbf{B}_{1} L-\cdots-\mathbf{B}_{p} L^{p}$ with $L$ being the lag operator, and $\mu$ is a vector of constants. The $\mathbf{u}_{t}$ stands for a vector of one-step-ahead forecast errors and we assume that $\mathbf{u}_{\mathbf{t}} \sim \mathcal{N}(\mathbf{0}, \boldsymbol{\Sigma})$ where $\Sigma$ is a symmetric positive definite matrix. It is important to note that in equation (4), $\mathbf{W}_{t}^{*}$ on the left hand side of the equation includes the latent variable $R_{t}^{*}$, while $\mathbf{W}_{t}$ on the right hand side of the equation includes the actual interest rate $R_{t}$, which is related to $R_{t}^{*}$ in a nonlinear way. This specific feature yields a model that exhibits interesting dynamics.

\subsection{Identification}

The structural form of the system (4) can be written as

$$
\mathbf{A}_{0} \mathbf{Z}_{t}^{*}=\mathbf{A}(L) \mathbf{Z}_{t}+\mathbf{A}_{0} \mu+\varepsilon_{t}
$$

where $\mathbf{Z}_{t}^{*}=\left[\mathbf{Y}_{t}^{\prime}, \mathbf{W}_{t}^{* \prime}, \mathbf{X}_{t}^{\prime}\right]^{\prime}, \mathbf{Z}_{t}=\left[\mathbf{Y}_{t}^{\prime}, \mathbf{W}_{t}^{\prime}, \mathbf{X}_{t}^{\prime}\right]^{\prime}$ and $\varepsilon_{t}=\left[\varepsilon_{t}^{Y \prime}, \varepsilon_{t}^{M \prime}, \varepsilon_{t}^{X \prime}\right]^{\prime}$ stands for the fundamental macroeconomic shocks. Note that $\varepsilon_{t}^{M}=\left(\varepsilon_{t}^{s}, \varepsilon_{t}^{d}\right)^{\prime}$ where $\varepsilon_{t}^{s}$ is the exogenous monetary policy shock and $\varepsilon_{t}^{d}$ is the exogenous money demand shock. We assume that $\varepsilon_{t} \sim \mathcal{N}\left(\mathbf{0}, \mathbf{I}_{m}\right)$.

We impose the following block recursive restrictions to identify the model. First, we assume that the exogenous money market shock $\varepsilon_{t}^{M}$ and the other financial market shock $\varepsilon_{t}^{X}$ do not affect output and price level $\left(\mathbf{Y}_{t}\right)$ in the 
same period, which is a quite standard identification restriction in the literature [e.g. Christiano et al (1999)] especially when monthly data are used. Second, we assume that the policy maker does not respond contemporaneously to the financial variable $\mathbf{X}_{t}$ when setting the interest rate, where $\mathbf{X}_{t}$ includes an aggregate stock price index in our estimation. We believe that this is a reasonable assumption for the following reason. Since the burst of the asset price bubble in 1990, the focus of Japanese monetary policy has shifted to fighting deflation and the economic slump. Even if the monetary authority does not completely ignore asset prices when setting its policy instrument, it no longer appears to be the systematic policy for the BoJ to respond to stock prices or some other financial variables contemporaneously after 1991.

These two assumptions together with the restrictions implied by the policy scheme of interest rate targeting (i.e. $R_{t}^{*}$ does not respond to the money demand shock $\varepsilon_{t}^{d}$ ) imply that the matrix $\mathbf{A}_{0}$ is block triangular. Rewrite (5) as

$$
\mathbf{Z}_{\mathbf{t}}^{*}=\mathbf{B}(L) \mathbf{Z}_{t}+\mu+\mathbf{C}_{\mathbf{0}} \varepsilon_{\mathbf{t}}
$$

where $\mathbf{C}_{0}$ is the matrix of the impact multipliers. Since $\mathbf{C}_{0}=\mathbf{A}_{0}^{-1}$, the matrix $\mathbf{C}_{0}$ is also a block lower triangular matrix ${ }^{6}$

$$
\mathbf{C}_{0}=\left[\begin{array}{ccc}
\mathbf{C}_{11} & \mathbf{0} & \mathbf{0} \\
\mathbf{C}_{21} & \mathbf{C}_{22} & \mathbf{0} \\
\mathbf{C}_{31} & \mathbf{C}_{32} & \mathbf{C}_{33}
\end{array}\right],
$$

which relates the fundamental shocks $\varepsilon_{t}$ to the VAR residual $u_{t}$.

Note that in the above matrix, $\mathbf{C}_{22}$ is an $l \times l$ lower triangular matrix, which imposes sufficient identifying restrictions to investigate the dynamic response of $\mathbf{Z}_{t}$ to a monetary policy shock $\varepsilon_{t}^{s}$ [see also Keating (1996)]. The system (6) subject to (1) and (7) can be estimated by the maximum likelihood method with additional necessary zero restrictions on $\mathbf{C}_{11}$ and $\mathbf{C}_{33}$. The Akaike's information criterion (AIC) is used to choose the number of lags in (6). The derivation of the likelihood function is provided in the Appendix.

When the economy is in liquidity trap, money demand is likely to behave quite differently than in the normal environment with positive interest

\footnotetext{
${ }^{6}$ Note that since we are not interested in identifying the money demand shock $\varepsilon_{t}^{d}$, it is just a simplification to assume that the money growth $\Delta m_{t}$ does not respond to the financial market shock $\varepsilon_{t}^{X}$ in the same period.
} 
rates. We therefore allow for the possibility that when the nominal interest rate is zero, money growth $\Delta m_{t}$ responds differently to $\varepsilon_{t}^{Y}$ as well as $\varepsilon_{t}^{M}$. Accordingly, the elements in the second row of matrices $\mathbf{C}_{21}$ and $\mathbf{C}_{22}$ have different values when the interest rate is at zero (the estimated coefficients on the zero-interest-rate dummies are reported in Table 2 below). We also allow for different intercept term for $\Delta m_{t}$ in model (6) when the zero bound is approached. ${ }^{7}$

Unlike in the linear case, the impulse response function (IRF) of the above VAR system is history- and shock-dependent [Potter (2000), Koop, Pesaran, and Potter (1996)]. This feature of the model allows us to investigate the effect of a monetary policy shock under two interest rate regimes, an issue we will discuss in more detail in the following sections.

\section{Results}

We estimate the nonlinear structural VAR model with the monthly data on Japanese wholesale price index, industrial output, the inter-bank call rate, the annual growth rate of money and the Nikkei stock price index (denoted by $\mathbf{Z}=(\mathbf{p}, \mathbf{y}, \mathbf{R}, \boldsymbol{\Delta} \mathbf{m}, \mathbf{x}))$ from 1991 to $2001 .^{8}$ Since our primary interest is in the dynamic responses of the variables, we do not report the point estimates of the VAR parameters here but only mention some features of the estimated model. First, Table 1 shows that the signs of the estimates of the elements in $\mathbf{C}_{\mathbf{2 1}}$ and $\mathbf{C}_{\mathbf{2 2}}$ are consistent with the counter-cyclical monetary policy pursued by the BoJ during that period. Namely, the BoJ takes expansionary policy actions by cutting the interest rate when facing a deflationary shock or a negative shock to output. (Notice the large and significant policy response to a positive shock to the price level $\left(\mathbf{C}_{21}(1,1)\right)$ in the table below.)

\begin{tabular}{ccl}
\multicolumn{3}{c}{ Table 1: Estimates of Policy Responses } \\
\hline $\mathbf{C}_{21}(1,1)$ & $\mathbf{C}_{21}(1,2)$ & $\mathbf{C}_{22}(1,1)$ \\
\hline .0634 & .0198 & .1882 \\
$(.0323)$ & $(.0335)$ & $(.0194)$ \\
\hline
\end{tabular}

\footnotetext{
${ }^{7}$ We also let the financial variable $\mathbf{X}_{t}$ respond differently to exogenous shocks under the zero interest rate regime. But we find the difference is small and insignificant.

${ }^{8}$ The 4 -variable VAR excluding the stock market price, that is $\mathbf{Z}=(\mathbf{p}, \mathbf{y}, \mathbf{R}, \boldsymbol{\Delta M})$, is also estimated. The results are very similar to those from the 5 -variable VAR.
} 
(Note: $\mathbf{C}_{21}$ is $2 \times 2$ matrix. $\mathbf{C}_{21}(1,1)$ measures the response of $R_{t}^{*}$ to a positive shock to the price level and $\mathbf{C}_{21}(1,2)$ measures the response of $R_{t}^{*}$ to a positive shock to output. $\mathbf{C}_{22}$ is a $2 \times 2$ lower triangular matrix. $\mathbf{C}_{22}(1,1)$ measures the standard deviation of monetary policy shocks. The numbers in parentheses are the standard errors.)

Second, nonlinearity is an important feature of the data because of the censorship and the different behavior of money demand when the interest rate is at zero. Figure 3 displays the fitted value of $R_{t}^{*}$ based on our VAR estimates together with the actually observed call rate. We can see that there are still large fluctuations in $R_{t}^{*}$ in the zero interest rate regime, indicating active policy movements during that period even when the actual interest rate rarely moves. The figure also shows that the estimates of the policy stance $R_{t}^{*}$ track the lower bound on the interest rate closely after 1995, consistent with the zero interest rate policy stated by the monetary authority. It is interesting to notice the sharp decreases in $R_{t}^{*}$ near the end of the sample period, implying that there were large monetary expansions in the second half of 2001. The BoJ has been criticized for conducting too tight monetary policy particularly after the interest rate had reached the zero bound. This significant easing of its policy suggests that the BoJ may have finally abandoned the zero interest rate policy and adopt a more expansionary monetary stance. Our estimates also confirm that there are significant differences in the behavior of money growth during the zero interest rate period. Table 2 reports the estimated coefficients on the zero-interest-rate dummies ( $q_{1}$ through $q_{4}$ ) that capture the differences in response of $\Delta m_{t}$ to the macroeconomic shock $\varepsilon_{t}^{Y}$ and money market shock $\varepsilon_{t}^{M}$

Table 2: Zero Interest Rate Dummies

\begin{tabular}{cccc}
\hline$q_{1}$ & $q_{2}$ & $q_{3}$ & $q_{4}$ \\
\hline-.0052 & -.0147 & .0060 & -.0386 \\
$(.0043)$ & $(.0051)$ & $(.0312)$ & $(.0186)$ \\
\hline
\end{tabular}

(Notes: The parameters $q_{1}$ and $q_{2}$ measure the additional impacts of a macro shock $\varepsilon_{t}^{Y}$ on money growth $\Delta m_{t}$ when the interest rate is at zero. The parameters $q_{3}$ and $q_{4}$ measure the additional impacts of a money market shock $\varepsilon_{t}^{M}$ on money growth $\Delta m_{t}$ when the interest rate is at zero. The numbers in parentheses are the standard errors.)

Based on the estimated VAR model, we now examine the dynamic responses of output, price, and other variables to an expansionary monetary 
policy shock when the interest rate is at zero and when it is positive. Our interest centers around the following two questions: (i) How much of the effect of an expansionary monetary policy shock on output is actually eliminated by the zero bound constraint on nominal interest rates? (ii) How important is the interest rate channel compared with other channels of monetary transmission?

The impulse response function (IRF) is often obtained by the difference of the h-steps-ahead forecast of the series with a current shock of a unit size from the same forecast without a shock. In a linear time series, this difference reduces to the h-th order parameters in its moving-average (MA) representation. In a vector auto-regression with a censored left hand variable, however, the MA representation is no longer linear in the shocks. As a result, the IRF for the nonlinear model is dependent upon the entire history of the series as well as the size and direction of the shock. This state-dependent feature of the IRF allows us to analyze the policy effects conditional on the current state of the system.

We follow the literature on nonlinear impulse response [Koop et al (1996), Gallant et al (1993), and Potter (2000)] and treat a nonlinear IRF as the difference between a pair of conditional expectations of the variables given a non-zero shock and a zero shock at the current period, i.e.

$$
E\left(\mathbf{Z}_{t+h} \mid \Omega_{t-1}, \varepsilon_{t}\right)-E\left(\mathbf{Z}_{t+h} \mid \Omega_{t-1}\right)
$$

where $\Omega_{t-1}$ stands for the information set at $t-1$, and $h=1,2, \cdots$ is the time horizon. In other words, to calculate the nonlinear IRF, we have to specify the nature of the shock (its size and sign) and the initial condition, $\Omega_{t-1}$. To calculate the conditional expectations, we simulate the model in the following manner. First, we randomly draw $\varepsilon_{t+j}$ from $\mathcal{N}\left(\mathbf{0}, \mathbf{I}_{\mathbf{m}}\right)$ for $j=$ $1,2, \cdots, h$ and then simulate the model conditional on an initial condition $\Omega_{t-1}$ and a particular shock $\varepsilon_{t}$. This process is repeated 500 times and the estimated conditional expectation is obtained as the average of the outcomes.

\subsection{The effects of monetary policy shocks when the interest rate is zero}

Figures 4(a) - 4(e) report the estimated impulse reponse functions (IRFs) of the variables included in our model. The solid and broken lines stand for, respectively, the IRFs of the variables to an expansionary monetary policy shock of size equal to one standard deviation when the interest rate is at zero 
and when it is positive. The horizontal axis measures the number of months after the shock. The IRF under each regime is calculated as an average of all the IRFs corresponding to the historical dates belonging to each of the two regimes: the regime where the call rate is at zero and the regime where it is positive. We find a striking difference in the IRFs under two regimes, which are consistent with the standard textbook explanation of the interest rate channel of monetary transmission.

When the interest rate is positive, we obtain the IRFs commonly observed in the standard monetary VAR literature. An expansionary policy shock decreases the nominal interest rate (Figure 4(c)), increases money growth (Figure 4(d)) and the aggregate price level (Figure 4(a)). The decrease in the nominal interest rate and the rising price level imply a much lower real interest rate which then leads to increases in real output (Figure 4(b)). The full impact on output reaches its peak in about 10 months after the initial monetary expansion. Moreover, the IRF of the aggregate price level exhibits the usual "price puzzle", where the price level initially declines under an expansionary monetary shock.

The same monetary policy shock, however, generates quite different dynamic responses of the macroeconomic variables when the interest rate is at the zero bound. While money growth and the price level continue to rise in response to the expansionary policy shock (Figure 4(d) and 4(a)), the nominal interest rate is constrained by the zero bound and can no longer fall (Figure 4(c)). As a result, although the rising price level still generate a lower real interest rate, the decrease in the real rate is only moderate, leading to much smaller increase in output. In fact, our estimates suggest that the peak impact of the monetary policy shock on output when the nominal interest rate is at zero is only about half the size of what the monetary policy can achieve when the rate is positive (Figure 4(b)). It is interesting to note that the IRF of the price level does not show the usual "price puzzle" under the zero interest rate regime.

The difference in the dynamic responses of output under two regimes provides an empirical estimate of the extent to which the zero bound constraint on interest rates impedes the transmission of monetary innovations. It suggests that the monetary authority cannot achieve the full effect of policy actions by continuing to target the nominal interest rate when the rate is stuck at zero. It also suggests that if the central bank generates high enough inflation, probably through some quantitative measures, so that the real interest rate decreases as much as in the normal circumstance, then it may 
be possible to overcome this zero interest rate constraint. We address this issue in a later section by exploring alternative monetary policy strategies.

Some economists such as Meltzer (1995) have argued that a monetary innovation not only changes a short-term interest rate, but also alters the relative prices of a variety of assets. To capture this effect of the policy shocks, we include an aggregate stock market price index in our VAR system. Figure 5 shows the stock price index indeed rises following an expansionary monetary shock, even when the nominal interest rate remains at zero. Such an increase in asset prices can have positive influence on real output either through the wealth effect on consumption or through a mechanism involving Tobin's q theory of investment. It can also magnify the interest rate channel impact through a credit channel effect [Bernanke and Gertler (1995)]. When the interest rate is always positive, it is difficult to separate empirically the effect of monetary policy shocks operating through the standard interest rate channel from those through any other channels. When the interest rate sometimes hits the zero bound, however, we can construct a pair of IRFs under two regimes and take the difference as a measure of the relative importance of the interest rate channel. More specifically, the difference of the responses of output provides a lower bound of the contribution of the interest rate channel because the real interest rate is still decreasing due to the rising price level even when the nominal rate is at zero. The large difference of the IRFs in Figure 4(b) appears to confirm that the interest rate channel is by far the most important monetary transmission.

\subsection{The impact of the zero interest constraint on counter cyclical monetary policy}

Some recent studies investigate the effect of the zero bound constraint on the ability of monetary authority to conduct effective policy [e.g Fuhrer and Madigan (1996), Orphanides and Wieland (1998) among others]. They use numerical simulation to find the extent to which a zero bound prevents the monetary authority from pursuing a counter cyclical interest-rate policy in response to negative macroeconomic shocks. We perform an analogous exercise by subjecting our VAR model to some adverse macroeconomic shocks to see how differently the system would respond depending on whether or not the interest rate is on the zero bound.

To conduct this exercise, we choose a macroeconomic shock (any mixture of inflation, output, and monetary shocks) that would generate an output 
decline for two consecutive quarters-the standard definition of a recession-in the normal situation. We then subject our VAR model to the same shock conditional on the interest rate being zero. Figures 6 and 7 display the IRFs of the interest rate and output, respectively. In the normal situation where the interest rate is not constrained, such a negative shock drives down output as well as the interest rate as the monetary authority pursues a counter cyclical policy. The resulting lower interest rate would eventually push the economy out of the recession. In contrast, if the interest rate is at zero when the adverse macroeconomic shock hits the economy, the monetary policy would lose much of its leverage against such a negative shock. Figures 6 and 7 show that the interest rate cannot fall any further, while the recovery is not only slower, but also weaker. If the interest rate is above zero when the negative shock hits the economy, the output will fully recover in about 14 months and then continues to rise about its original level. But if the interest rate is at zero when the shock hits the economy, it would take more than 20 months for output to barely come back to its original level.

An alternative way to look at the impact of the zero bound constraint is to postulate a hypothetical situation in which the zero bound constraint is entirely removed. How differently would the economy evolve after 2001 with stochastic macroeconomic shocks with and without the zero bound constraint? We simulate the estimated VAR starting from the last sample period, and compare the dynamics of output and the interest rate. Figures 8 and 9 display the results from such an exercise. We can see that without zero bound constraint, the interest rate would become significantly negative, which in turn stimulates the economy and output rises faster and reaches a level much higher than it would be with the constraint. One major caveat of such a comparison is obviously that the model parameters are estimated while imposing the zero bound constraint. Nevertheless, the large discrepancy between the two output series in Figure 9 suggests that the zero bound has a significant impact on the macro economic performance of the economy.

\subsection{Targeting money growth when the interest rate is at zero}

The BoJ has been criticized for not being aggressive enough to combat persistent deflation and prolonged economic stagnancy. Many critics argue that effective monetary policy requires quantitative easing when the interest rate is stuck at zero. The sharp decline of our latent policy variable $R_{t}^{*}$ near the end of our sample period (Figure 3) suggests that the BoJ might have 
indeed started to take alternative policy actions under increasing pressures. In this section we estimate the effect of such quantitative measures when the interest rate is at the zero bound.

Specifically, if the BoJ decided to target money growth after the interest rate was pushed down to zero, equation (2) and (3) would be replaced by (abstracting from all the lagged variables)

$$
\begin{aligned}
R_{t}^{*} & =\tilde{\beta}_{1}^{\prime} \varepsilon_{t}^{Y}+\tilde{\beta}_{2} \varepsilon_{t}^{s}+\tilde{\beta}_{3} \varepsilon_{t}^{d} \\
\Delta m_{t} & =\tilde{\alpha}_{1}^{\prime} \varepsilon_{t}^{Y}-\tilde{\alpha}_{2} \varepsilon_{t}^{s}
\end{aligned}
$$

where $\varepsilon_{t}^{s}$ is the exogenous policy shock, and $\varepsilon_{t}^{d}$ is the exogenous money demand shock, $\varepsilon_{t}^{Y}$ the vector of innovations to the macroeconomic variables to which the monetary policy respond contemporaneously. Under this policy scheme, the monetary authority does not accommodate the exogenous money demand shocks. Therefore, even when the interest rate is initially at zero, a positive money demand shock $\varepsilon_{t}^{d}$ could push $R_{t}^{*}$ above zero, resulting in an increase in the observed interest rate $R_{t}$. On the other hand, a negative money demand shock $\varepsilon_{t}^{d}$ pushes $R_{t}^{*}$ down. If the interest rate is already at the zero bound, such a shock does not generate any movement in $R_{t}$. Equation (9) implies that $\Delta m_{t}$ is only affected contemporaneously by the exogenous monetary policy shock $\varepsilon_{t}^{s}$ (in addition to $\varepsilon_{t}^{Y}$ ), as in the standard case of money targeting. Note that we allow the coefficients on $\varepsilon_{t}^{Y}$ and $\varepsilon_{t}^{s}$ to take on different values when the interest rate is at zero (equation (8) and (9)) from those when the interest rate is positive (equation (2) and $(3))$.

Unfortunately, the VAR model incorporating the above structure is observationally equivalent to the VAR model discussed in section 3 . Therefore, it is simply not possible to test whether such quantitative measures are part of the current policy mix by comparing (8) and (9) with (2) and (3). However, it is still possible to use the above specification to investigate the effects of exogenous monetary policy shocks assuming the BoJ had switched its policy instrument to quantitative measures when the interest rate is on the zero bound. In particular, we estimate a VAR model similar to (6) and (7), assuming that the monetary authority targets the interest rate (as in (2) and (3)) when $R_{t}>0$ but switches to target money growth (as in (8) and (9)) when $R_{t}=0$.

Figure 10 displays the reactions of the aggregate price level, real output, the interest rate and money growth to an exogenous expansionary policy shock under both positive and zero interest rate regimes. It shows that if 
monetary authority switches its operating target to money growth when the interest rate is at zero, the effect of a monetary shock on output would be almost as strong as when the interest rate is positive. In contrast, the zero bound can eliminate almost $50 \%$ of the output effect of policy shocks if the monetary authority continues to target the interest rate as found in Figure 4.

Examining Figures 4 and 10 helps find the possible source of this large difference. If the monetary authority switches its target to money growth when the interest rate is at zero, an exogenous monetary expansion would generate a price increase so large (Figure 10(a)) that even though the nominal rate is stuck at zero (Figure 10(c)), there would be enough decline in the real interest rate to push up the level of output (Figure 10(b)). However, if the monetary authority continues to target the interest rate, the impact of the monetary expansion on the price level is not large enough (Figure 4(a)) to offset the negative impact of the zero interest rate (Figure 4(c)). As a result, monetary policy becomes much less effective (Figure 4(b)).

Since we cannot test which scheme is a better description of the true monetary behavior under the zero interest rate regime, the above estimates are subject to the caveat of "identification errors". The BoJ has repeatedly made it public that it is pursuing an interest rate targeting policy through out the sample period. To the extent this is true, the results reported in Figure 4 give us the empirical estimates of the effect of the zero bound on the interest rate channel of monetary transmission. If the true policy is a mixture of both interest rate and money targeting, our results reported in Figure 10 would provide direct empirical evidence favoring quantitative measures as a way to conduct effective monetary policy when the interest rate is on the zero lower bound.

\section{Concluding remarks}

In this paper we estimate the effect of an exogenous monetary shock when nominal interest rates are at zero and examine the impacts of the zero bound constraint on the effectiveness of counter-cyclical monetary policy. While there are many recent studies trying to evaluate the extent to which the zero bound interferes with the conduct of monetary policy by simulating structural models of the U.S. economy, those quantitative results are inevitably model specific and often lack direct empirical support. The low 
interest rates and the apparent presence of the liquidity trap in Japan during the past decade make it possible to address such issues empirically using a nonlinear structural VAR.

We find that when the the interest rate is on the zero bound, up to $50 \%$ of the impact of an exogenous monetary innovation on output can be eliminated if the monetary authority continues to target the interest rate. The conditional IRFs allow us to isolate the impact of monetary shocks operating through the interest rate channel when other possible channels of monetary transmission are present. We find that (i) an exogenous monetary shock may still have a significant effect on the real economy when nominal interest rates are at zero, (ii) it is the interest rate channel that appears to be the most important mechanism of monetary transmission. Moreover, we also find that the presence of the zero bound on nominal interest rates could severely limit the ability of central banks to pursue a counter-cyclical interest rate policy when facing adverse macroeconomic shocks.

It is often debated whether or not the BoJ should conduct a further monetary easing given the stagnant domestic economy and the zero bound constraint on its policy instrument. This paper provides some empirical evidence supporting the view that the monetary authority can rely on quantitative measures to conduct an effective monetary policy when the interest rate is on the zero bound. 


\section{Appendix}

\section{Derivation of the likelihood function:}

We first rearrange the order of the variables in $\mathbf{Z}_{t}^{*}$. Define

$$
\mathbf{J}=\left[\begin{array}{lll}
\mathbf{0} & 1 & \mathbf{0} \\
\mathbf{I}_{k} & \mathbf{0} & \mathbf{0} \\
\mathbf{0} & \mathbf{0} & \mathbf{I}_{n+1}
\end{array}\right]
$$

so that $\mathbf{J}^{\prime} \mathbf{J}=\mathbf{I}_{m}$. Rewrite (1) as

$$
\mathbf{J B}(L) \mathbf{J}^{\prime} \mathbf{J} \mathbf{Z}_{t}^{*}=\mathbf{J} \mu+\mathbf{J} \mathbf{C}_{0} \mathbf{J}^{\prime} \mathbf{J} \varepsilon_{t}
$$

or

$$
\widetilde{\mathbf{B}}(L) \widetilde{\mathbf{Z}}_{t}^{*}=\widetilde{\mu}+\widetilde{\mathbf{C}}_{0} \widetilde{\varepsilon}_{t}
$$

where $\widetilde{\mathbf{B}}(L)=\mathbf{J B}(L) \mathbf{J}^{\prime}, \widetilde{\mathbf{C}}_{0}=\mathbf{J C}_{0} \mathbf{J}^{\prime}, \widetilde{\mu}=\mathbf{J} \mu, \widetilde{\mathbf{Z}}_{t}^{*}=\left[R_{t}^{*},\left[\mathbf{Y}_{t}^{\prime}, \mathbf{X}_{t}^{\prime}\right]\right]^{\prime}=$ $\left[Z_{1 t}^{*}, \mathbf{Z}_{2 t}^{* \prime}\right]^{\prime}$ and $\widetilde{\varepsilon}_{t}=\left[\varepsilon_{t}^{M}, \varepsilon_{t}^{Y \prime}, \varepsilon_{t}^{X \prime}\right]^{\prime} \sim \mathcal{N}\left(\mathbf{0}, \mathbf{I}_{m}\right)$.

Write $\widetilde{\mathbf{B}}=\left[\widetilde{\mathbf{B}}_{1}, \cdots, \widetilde{\mathbf{B}}_{p}, \widetilde{\mu}\right]$ and $\widetilde{\mathbf{Z}}^{* t}=\left[\widetilde{\mathbf{Z}}_{t-1}^{* \prime}, \cdots, \widetilde{\mathbf{Z}}_{t-p}^{* \prime}, 1\right]^{\prime}$. Then we have

$$
\widetilde{\mathbf{Z}}_{t}^{*}=\widetilde{\mathbf{B}} \widetilde{\mathbf{Z}}^{* t}+\widetilde{\mathbf{u}}_{t}
$$

with $E\left(\widetilde{\mathbf{u}}_{t} \widetilde{\mathbf{u}}_{t}^{\prime}\right)=\boldsymbol{\Sigma}=\left[\begin{array}{cc}\widetilde{\sigma}_{11} & \widetilde{\mathbf{\Sigma}}_{12} \\ \widetilde{\mathbf{\Sigma}}_{21} & \widetilde{\boldsymbol{\Sigma}}_{22}\end{array}\right]=\widetilde{\mathbf{C}}_{0} \widetilde{\mathbf{C}}_{0}^{\prime}=\mathbf{J C}_{0} \mathbf{C}_{0}^{\prime} \mathbf{J}^{\prime}$.

The likelihood function conditional on $\left(\widetilde{\mathbf{Z}}_{0}, \cdots, \widetilde{\mathbf{Z}}_{1-p}\right)$ is given by

$$
\begin{aligned}
L & =\prod_{R_{t}^{*} \geq c} f\left(\widetilde{Z}_{1 t}, \widetilde{\mathbf{Z}}_{2 t}\right) \prod_{R_{t}^{*}<c} \int_{-\infty}^{c} f\left(\widetilde{Z}_{1 t}, \widetilde{\mathbf{Z}}_{2 t}\right) d \widetilde{Z}_{1 t} \\
& =\prod_{R_{t}^{*} \geq c} f\left(\widetilde{Z}_{1 t}, \widetilde{\mathbf{Z}}_{2 t}\right) \prod_{R_{t}^{*}<c} f\left(\widetilde{\mathbf{Z}}_{2 t}\right) \int_{-\infty}^{c} f\left(\widetilde{Z}_{1 t} \mid \widetilde{\mathbf{Z}}_{2 t}\right) d \widetilde{Z}_{1 t}
\end{aligned}
$$

Noting that $\widetilde{u}_{1 t}=\widetilde{\boldsymbol{\Sigma}}_{12} \widetilde{\boldsymbol{\Sigma}}_{22}^{-1} \widetilde{\mathbf{u}}_{2 t}+e_{t}$ where $e_{t} \sim \mathcal{N}\left(0, \widetilde{\sigma}_{11 \cdot 2}^{2}\right)$ with $\widetilde{\sigma}_{11 \cdot 2}^{2}=$ $\widetilde{\sigma}_{11}^{2}-\widetilde{\boldsymbol{\Sigma}}_{12} \widetilde{\boldsymbol{\Sigma}}_{22}^{-1} \widetilde{\boldsymbol{\Sigma}}_{21}$, we find

$$
\widetilde{Z}_{1 t} \mid \widetilde{\mathbf{Z}}_{2 t} \sim \mathcal{N}\left(\mu_{1 \cdot 2}, \widetilde{\sigma}_{11 \cdot 2}^{2}\right)
$$


where $\mu_{1 \cdot 2}=\left(\widetilde{\mathbf{B}}_{1}-\widetilde{\boldsymbol{\Sigma}}_{12} \widetilde{\boldsymbol{\Sigma}}_{22}^{-1} \widetilde{\mathbf{B}}_{2}\right) \widetilde{\mathbf{Z}}^{t}+\widetilde{\mathbf{\Sigma}}_{12} \widetilde{\boldsymbol{\Sigma}}_{22}^{-1} \widetilde{\mathbf{Z}}_{2 t}$ and $\widetilde{\mathbf{B}}=\left[\widetilde{\mathbf{B}}_{1}^{\prime}, \widetilde{\mathbf{B}}_{2}^{\prime}\right]^{\prime}$. Hence, the log likelihood function takes the form as

$$
\begin{aligned}
\ln L & \propto-\left(T_{1} / 2\right) \ln \left|\widetilde{\mathbf{C}}_{0} \widetilde{\mathbf{C}}_{0}^{\prime}\right| \\
& -(1 / 2) \sum_{R_{t}>c}\left(\widetilde{\mathbf{Z}}_{t}-\widetilde{\mathbf{B}} \widetilde{\mathbf{Z}}^{t}\right)^{\prime}\left(\widetilde{\mathbf{C}}_{0} \widetilde{\mathbf{C}}_{0}^{\prime}\right)^{-1}\left(\widetilde{\mathbf{Z}}_{t}-\widetilde{\mathbf{B}} \widetilde{\mathbf{Z}}^{t}\right)-(T / 2) \ln \left|\widetilde{\mathbf{\Sigma}}_{22}\right| \\
& -(1 / 2) \sum_{R_{t}=c}\left(\widetilde{\mathbf{Z}}_{2 t}-\widetilde{\mathbf{B}}_{2} \widetilde{\mathbf{Z}}^{t}\right)^{\prime}\left(\widetilde{\mathbf{\Sigma}}_{22}^{0}\right)^{-1}\left(\widetilde{\mathbf{Z}}_{2 t}-\widetilde{\mathbf{B}}_{2} \widetilde{\mathbf{Z}}^{t}\right)+\sum_{R_{t}=c} \ln \Phi\left(\frac{c-\mu_{1 \cdot 2}^{0}}{\widetilde{\sigma}_{11 \cdot 2}^{0}}\right)
\end{aligned}
$$

where $T_{1}$ stands for the number of observations for which $R_{t}>c$. 


\section{References}

[1] Bernanke, B. S. and M. Gertler (1995) "Inside the Black Box: The Credit Channel of Monetary Policy Transmission," Journal of Economic Perspective 9, 27-48.

[2] Buiter, W. H. and N. Panigirtzoglou (1999) "Liquidity Traps: How to Avoid Them and How to Escape Them," NBER Working Paper 7245, National Bureau of Economic Research.

[3] Christiano, L. J. (2000) "Comments on Ben McCallum, "Theoretical Analysis Regarding a Zero Lower Bound on Nominal Interest Rates'," Journal of Money, Credit, and Banking 32, 905-930.

[4] Christiano, L. J., M. Eichenbaum, and C. L. Evans (1999) "Monetary Policy Shocks: What Have We Learned and to What End?," Handbook of Macroeconomics.

[5] Clouse, J., D. Henderson, A. Orphanides, D. Small, and P. Tinsley (2000) "Monetary Policy When the Nominal Short-Term Interest Rate is Zero," Finance and Economics Discussion Paper, Federal Reserve Board.

[6] Eichenbaum, M. and C. Evans (1995) "Some Empirical Evidence on the Effects of Shocks to Monetary Policy on Exchange Rates" Quarterly Journal of Economics 110, 975-1009.

[7] Fuhrer, J. C., and B. F. Madigan (1997) "Monetary Policy when Interest Rates are Bounded at Zero," Review of Economics and Statistics $79,573-585$.

[8] Hertzel, L. H. (1999) "Japanese Monetary Policy: A Quantity Theory Perspective," Federal Reserve Bank of Richmond Economic Quarterly $85,1-25$.

[9] Keating, J. (1996) "Structural Information in Recursive VAR orderings," Journal of Economic Dynamics and Control 20, 1557 - 1580.

[10] Koop, G., M. H. Pesaran, and S. M. Potter (1996) "Impulse Response Analysis in Nonlinear Multivariate Models," Journal of Econometrics $74,119-147$.

[11] Gallant, A. R., P. E. Rossi, and G. Tauchen (1993) "Nonlinear Dynamic Structures," Econometrica 61, 871-907. 
[12] Krugman, P. (1998) 'It's Baaack: Japan's Slump and the Return of the Liquidity Trap," Brookings Paper on Economic Activity 2, 137-187.

[13] McCallum, B. T. (2000a) "Theoretical Analysis Regarding a Zero Lower Bound on Nominal Interest Rates," Journal of Money, Credit, and Banking 32, 870-904.

[14] McCallum, B. T. (2000b) "Alternative Monetary Policy Rules: A Comparison with Historical Settings for the United States, the United Kingdom, and Japan," Federal Reserve Bank of Richmond Economic Quarterly 86, 49-79.

[15] McCallum, B. T. (2001) "Inflation Targeting and The Liquidity Trap," NBER Working Paper 8225, National Bureau of Economic Research.

[16] Meltzer, A. H. (1995) "Monetary, Credit and (Other) Transmission Processes: A Monetarist Perspective," Journal of Economic Perspective $9,49-72$.

[17] Meltzer, A. H. (2001) "Monetary Transmission at Low Inflation: Some Clues from Japan in the 1990s," The Bank of Japan Monetary and Economic Studies, 13-34.

[18] Mishkin, F. S. (1995) "Symposium on the Monetary Transmission Mechanism," Journal of Economic Perspective 9, 3-10.

[19] Okina, K., and N. Oda (2000) "Further Monetary Easing Policies under Non-negativity Constraints of Nominal Interest Rates: Summary of Discussion Based on Japan's Experience," Working Paper, Bank of Japan.

[20] Orphanides, A., and V. Wieland (1998) "Price Stability and Monetary Effectiveness when Nominal Interest Rates are Bounded at Zero," Finance and Economics Discussion Paper 1998-35, Federal Reserve Board.

[21] Rotemberg, J. J. and M. Woodford (1997) "An Optimization-Based Econometric Framework for the Evaluation of Monetary Policy," (with discussion) in B. S. Bernanke and J. J. Rotemberg, eds., NBER Macroeconomic Annual 1997, Cambridge, Mass.: MIT Press, 297-361.

[22] Potter, S. M. (2000) "Nonlinear Impulse Response Functions," Journal of Economic Dynamics $\&$ Control 24, 1425-1446. 
[23] Reifschneider, D. and J. C. Williams (2000) "Three Lessons for Monetary Policy in a Low Inflation Era," Journal of Money, Credit, and Banking 32.

[24] Svensson, L. E. O. (2000) "The Zero Bound in an Open Economy: A Foolproof Way of Escaping from a Liquidity Trap," the paper presented in Bank of Japan international conference, The Role of Monetary Policy under Low Inflation: Deflationary Shocks and Their Policy Responses, held in Tokyo, July 2000.

[25] Taylor, J. B. (1995) "The Monetary Transmission Mechanism: An Empirical Framework," Journal of Economic Perspective 9, 11-26.

[26] Wolman, A. L. (1998) "Staggered Price Setting and the Zero Bound on Nominal Interest Rates," Federal Reserve Bank of Richmond Economic Quarterly 84, 1-24. 


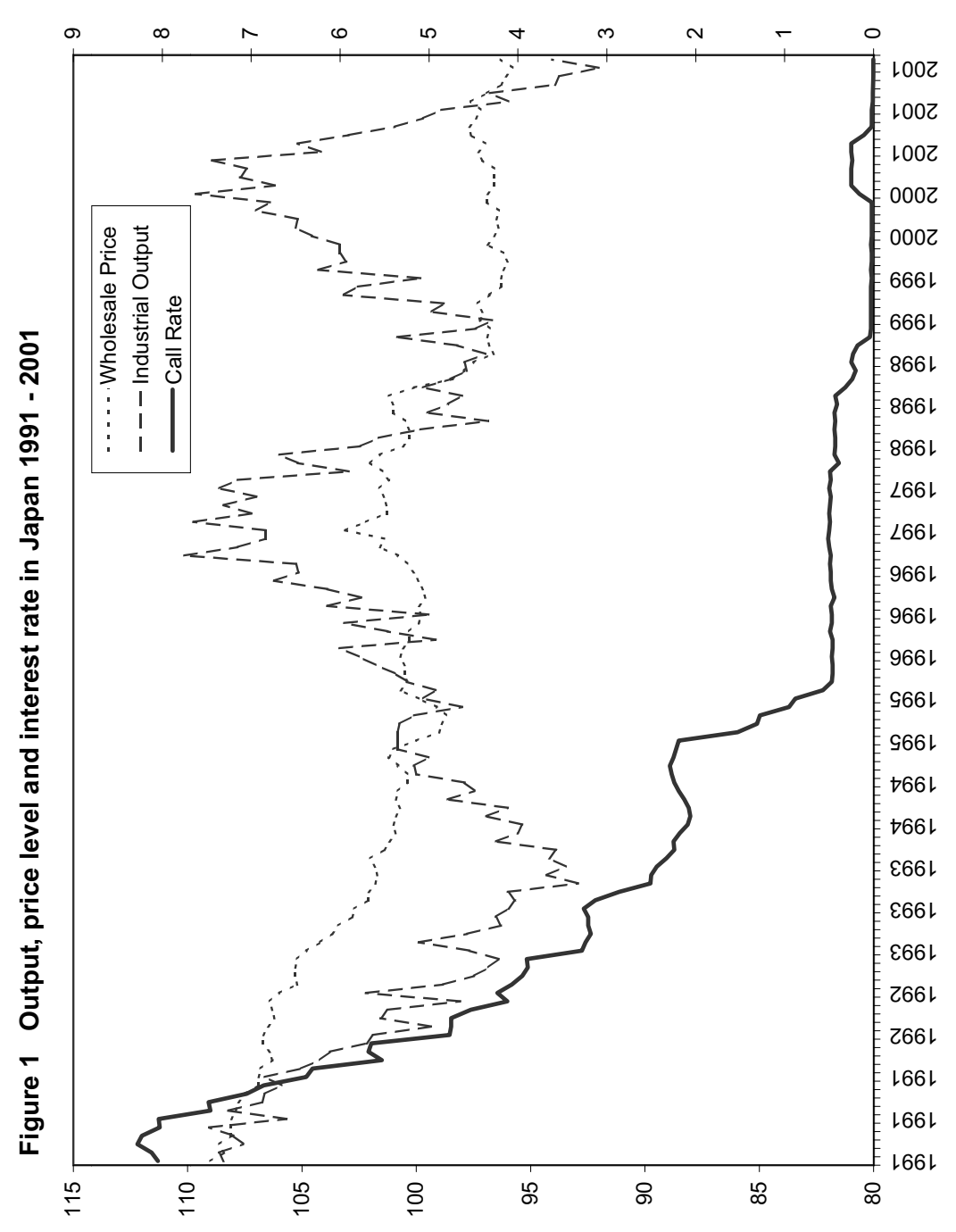


Figure 2. Money and Interest Rate

Money market when $\mathrm{R}>0$

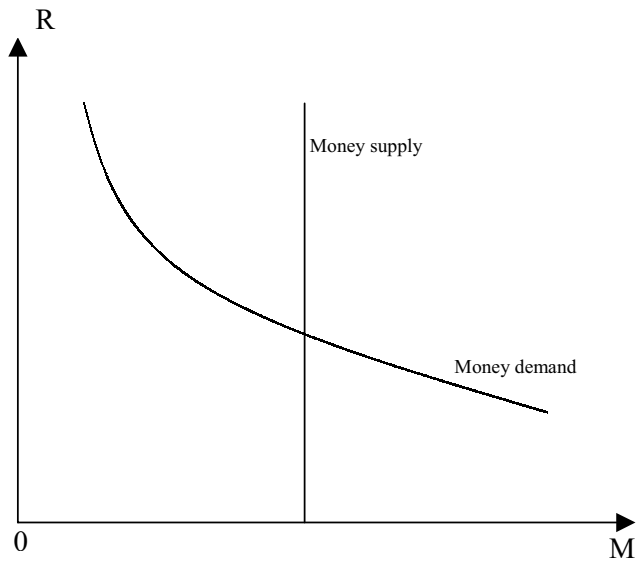

Money market when $\mathrm{R}=0$

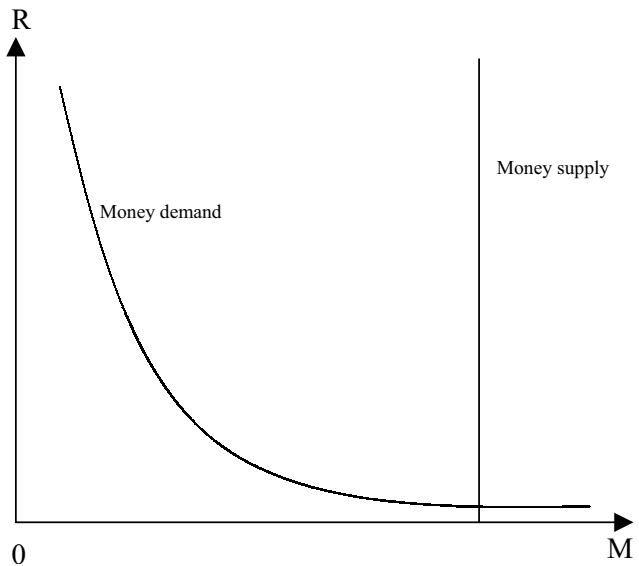




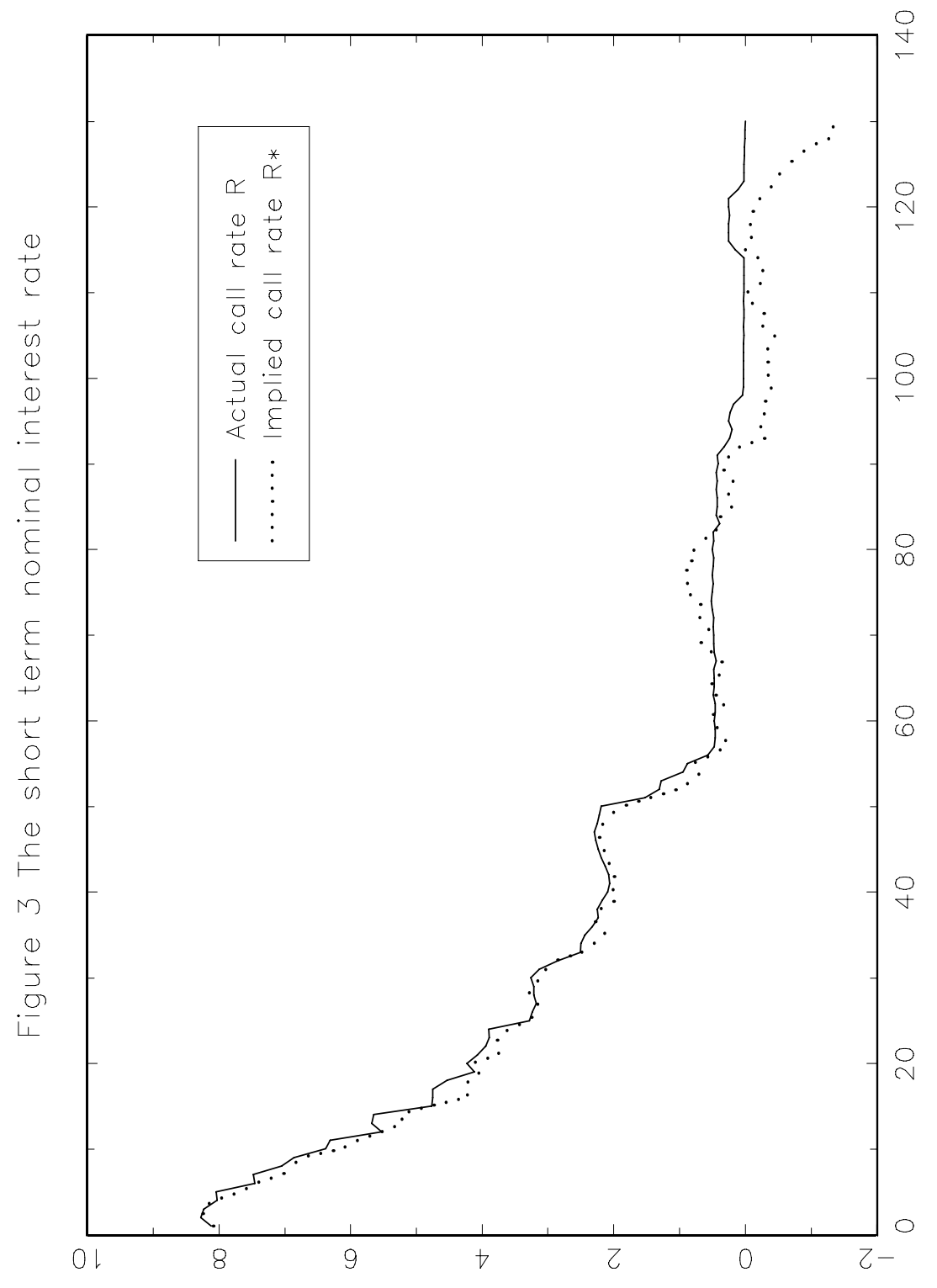



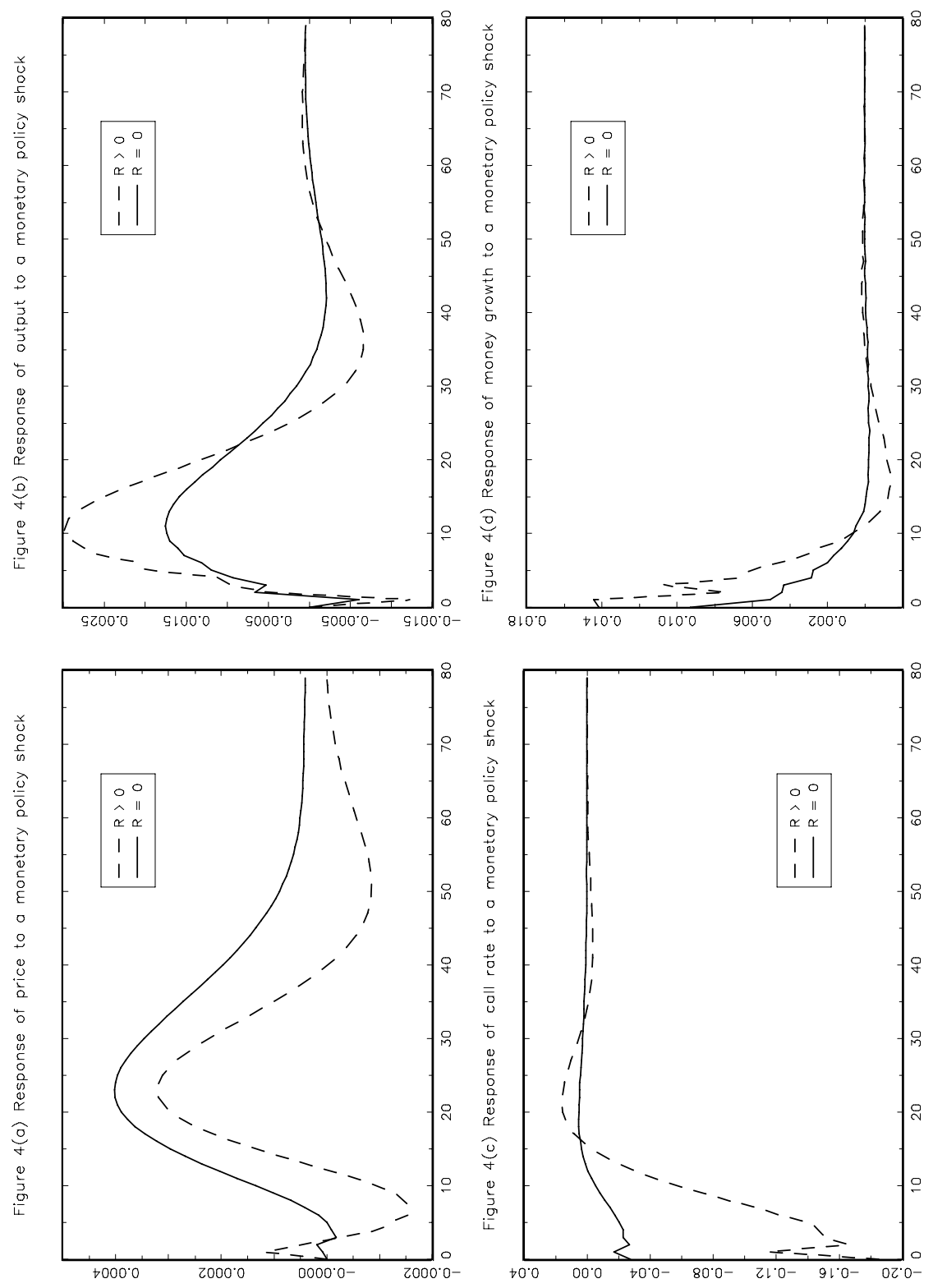


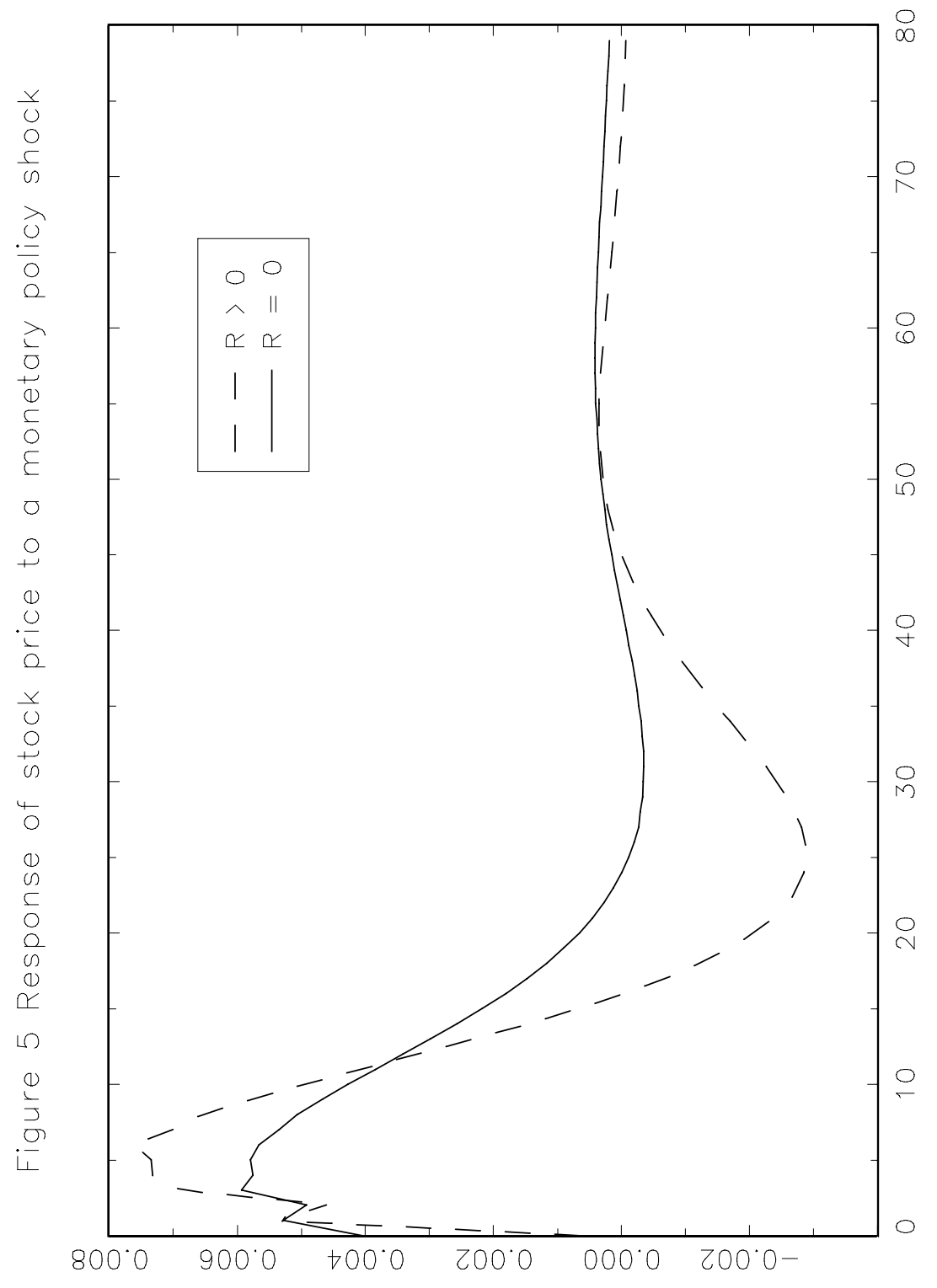




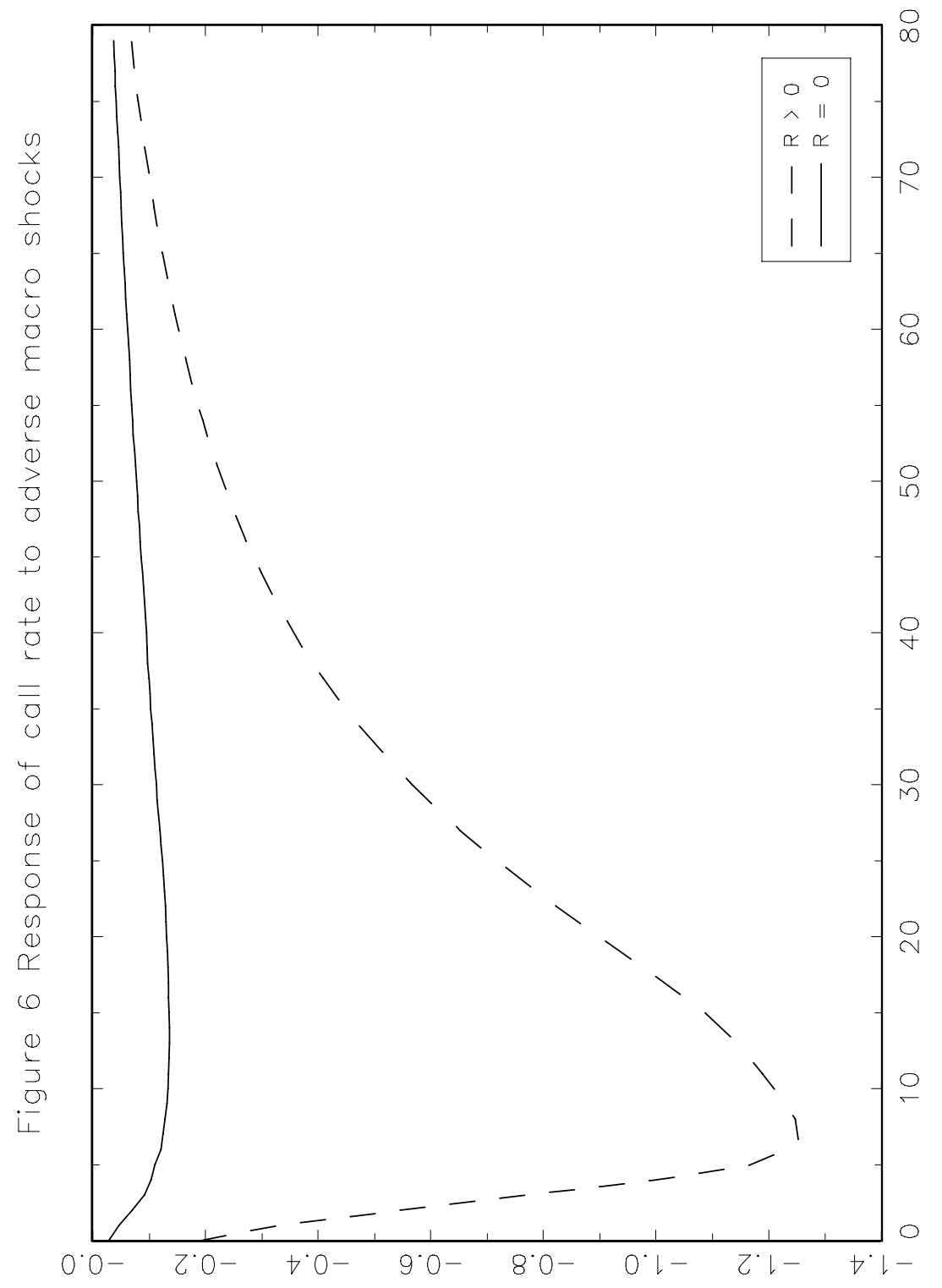




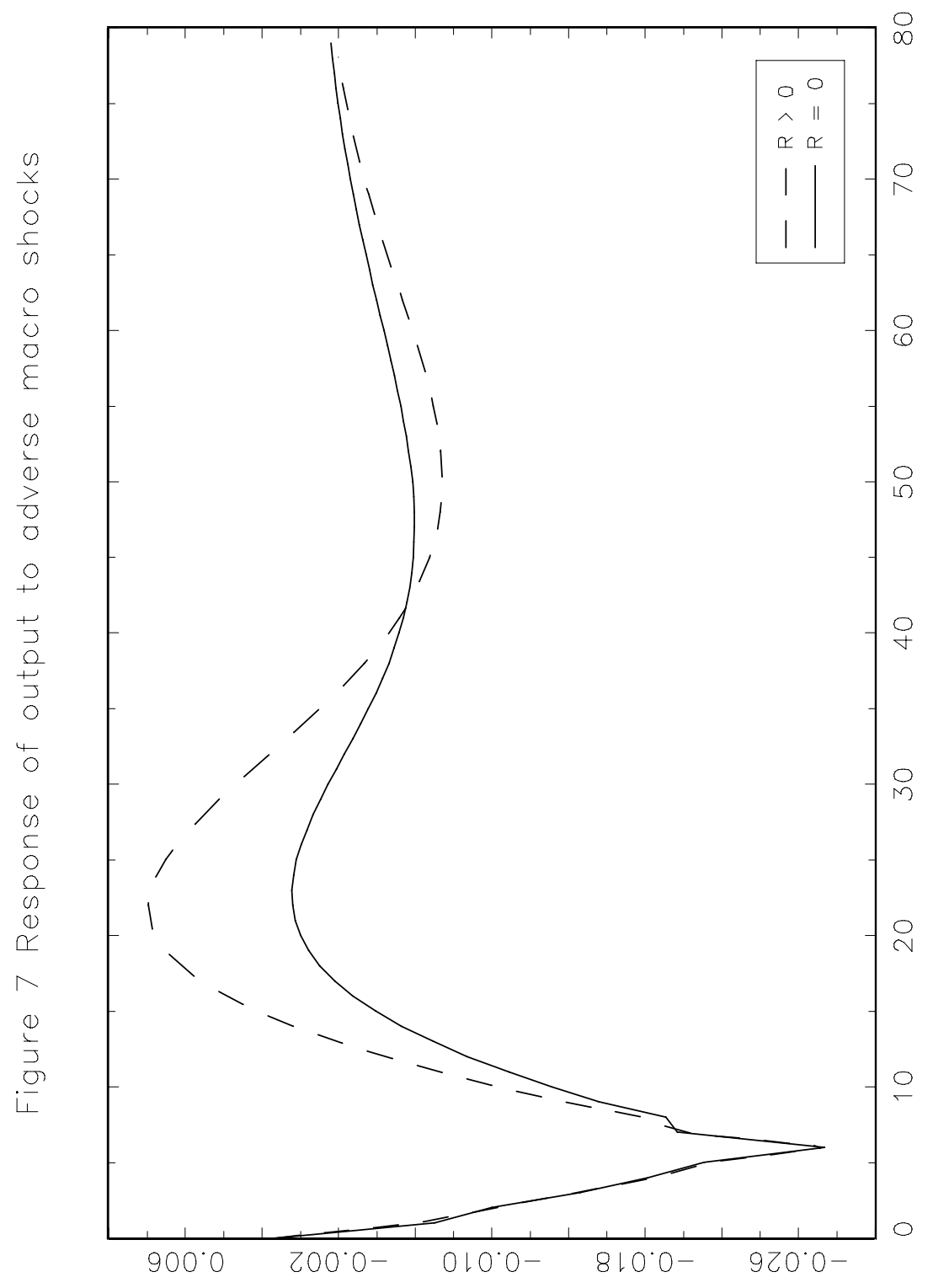




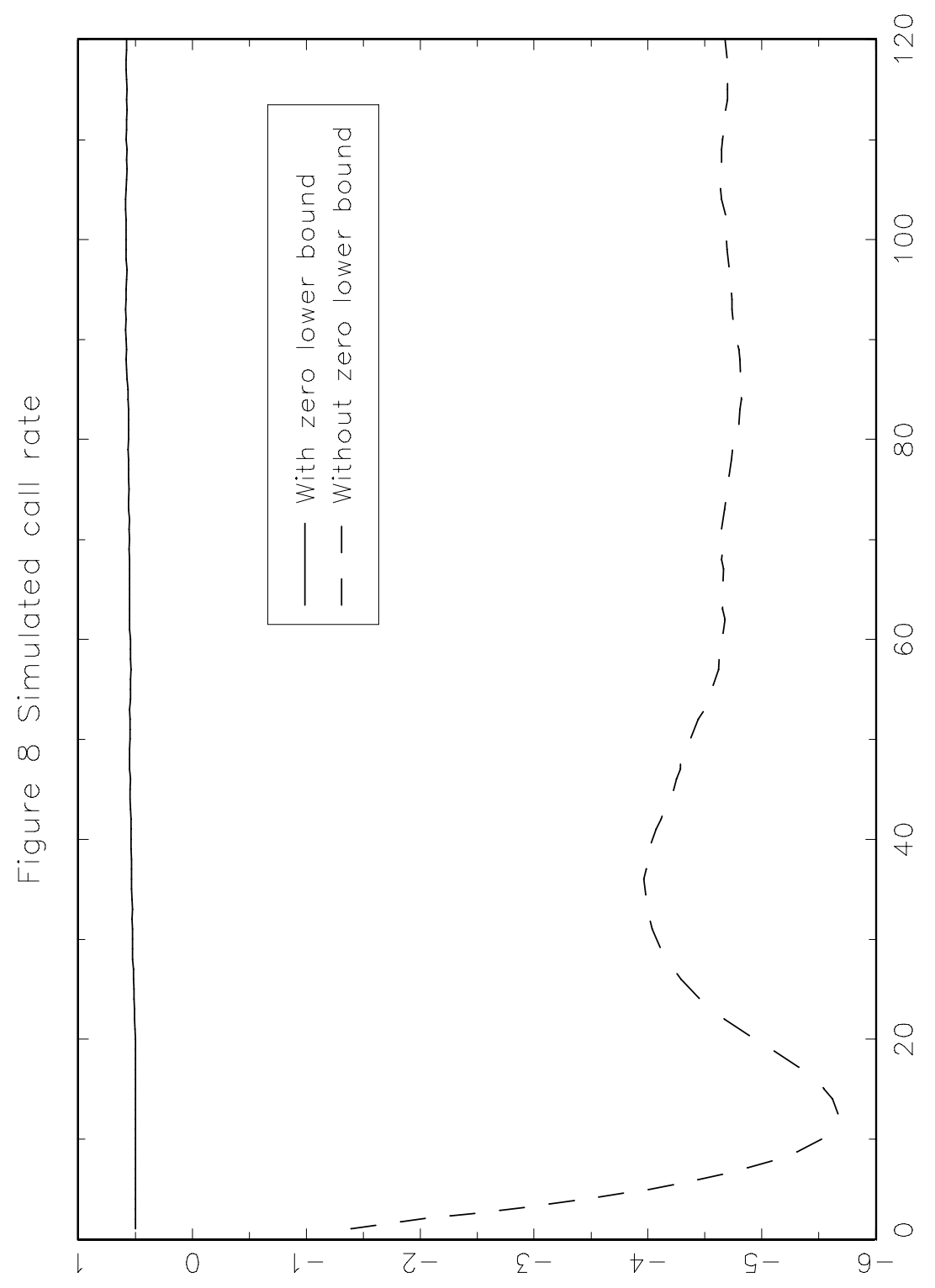




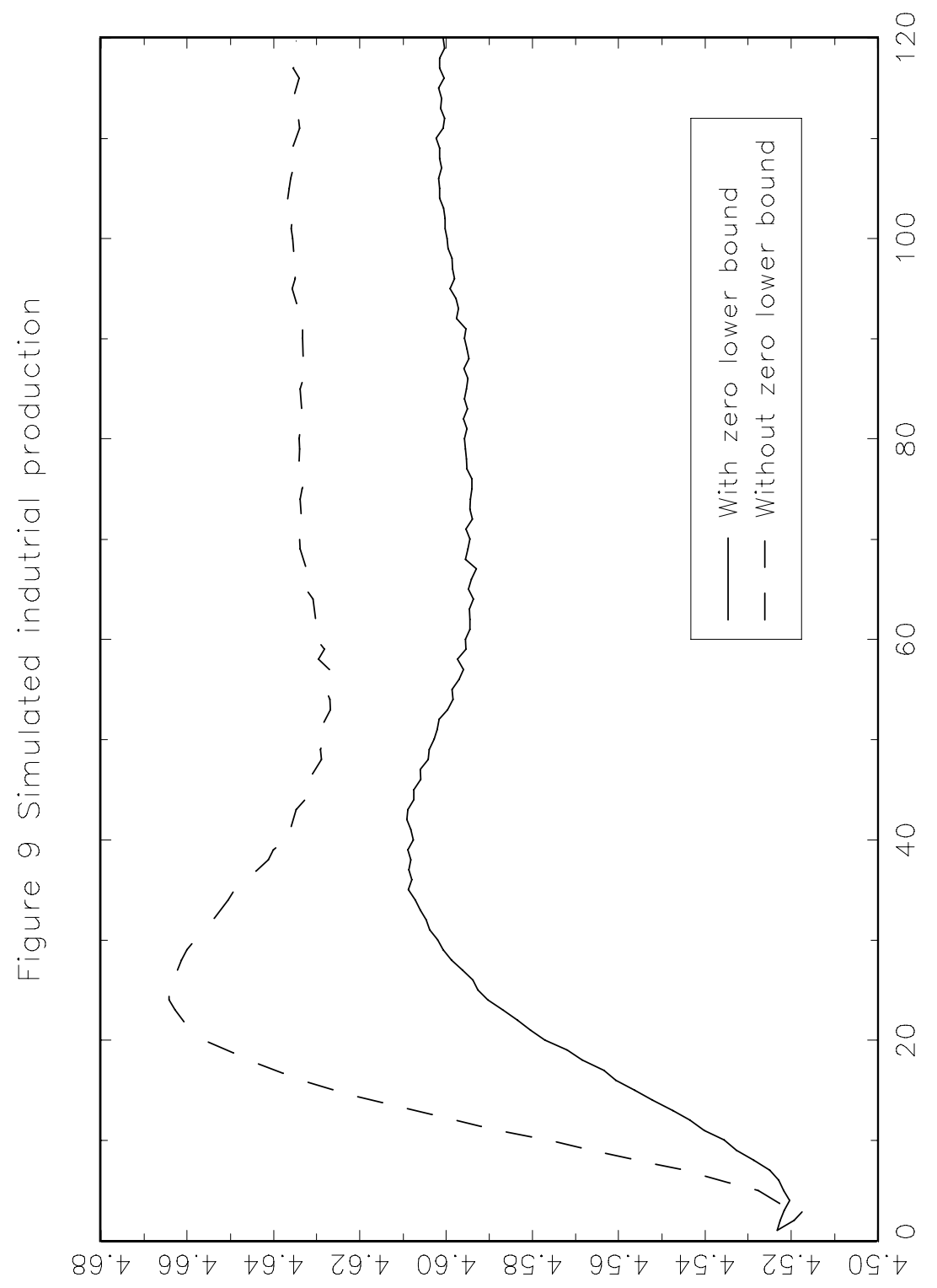



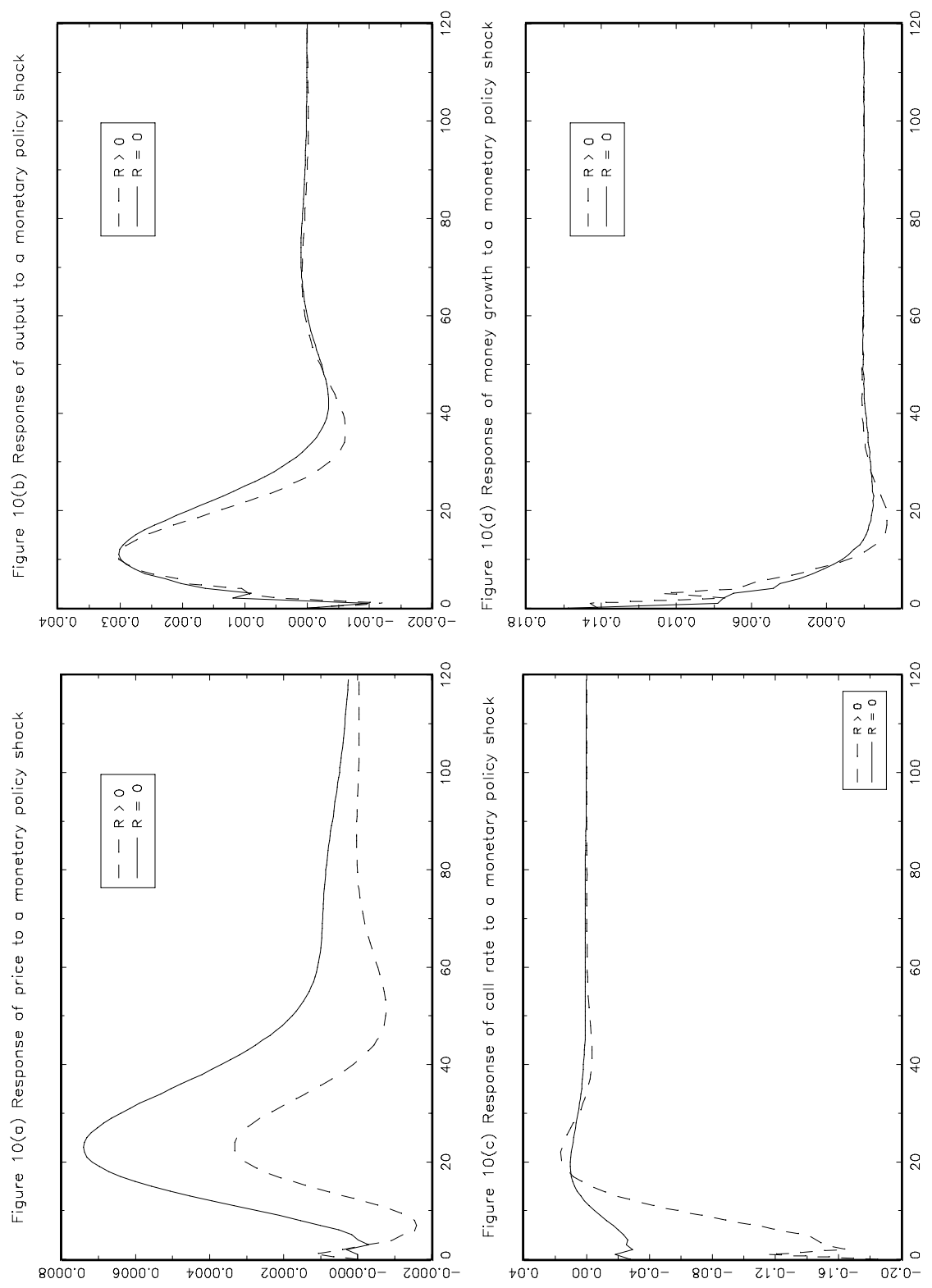